\title{
Comparing the Efficacy of Closantel (An Anthelmintic Drug) and Azadirachta indica (Neem Plant) Diet in Controlling Trichostrongylid Nematode Parasites in Goats in Malaysia
}

\author{
Wahab A. Rahman* \\ School of Food Science and Technology, Universiti Malaysia Terengganu, \\ Kuala Terengganu 21300 Malaysia \\ *Corresponding author
}

A B S T R A C T

Keywords

Efficacy, closantel, Azadirachta indica diet, control, trichostrongylid nematodes, goats, Malaysia.

Article Info

Accepted:

20 September 2016

Available Online:

10 October 2016
This study was conducted to compare the efficacy of closantel, an anthelmintic drug and neem plant diet (Azadirachta indica) against trichostrongylid nematode parasites of goats. Fecal egg counts (FEC) using modified McMaster and prevalence of nematode species in goats were investigated. Results indicated that the Fecal Egg Count Reduction Test (FECRT) for closantel was low, with approximately $29.22 \%$, while FECRT for neem (A. indica) was lower than closantel at $4.25 \%$. Both treated groups had no significant difference to the control group at $\mathrm{P}<0.05$. Larval cultures of fecal samples revealed that Haemonchus spp. was the predominant species infecting the goats.

\section{Introduction}

Helminthiasis or infection with gastrointestinal nematodes such as Haemonchus contortus is a common problem in grazing animals which can lead to poor animal performance and economic loss to the livestock industry (Waller \& Thamsborg, 2004). In Malaysia, the main methods of controlling gastrointestinal nematodes is using chemical anti-parasitic drug or anthelmintic and also by maintaining good pasture management (Rahman, 1994). As a result of frequent and unsupervised use of a wide variety of anthelminthic classes such as benzimendazoles, imidothiazoles and macrocyclic lactones, the helminth parasite has developed anthelminthic resistance which can lead to total failure of modern broad spectrum anthelminthic to control internal parasites of goats (Chandrawathani et al., 2004).

Researches on finding alternatives to commercially available anthelminthic are rapidly increasing in order to combat resistance (Dorny et al., 1994; Rahman 1994; Pandey and Sivaraj, 1994; Sivaraj et al., 1994; Chandrawathani et al., 1994). The 
increasing awareness in finding alternative anthelminthic from various plants has significantly reduced nematode parasite in small ruminants, with Azadirachta indica plant as a potential candidate for controlling worm problem (Chandrawathani et al., 2002).

The present study was initiated with the objective of determining the status of closantel efficacy and to compare with the anthelmintic activity of the Neem plant (Azadirachta indica) in controlling the helminthiasis problem in goats in Malaysia.

\section{Materials and Methods}

\section{Study Area and experimental animals}

A privately owned goat farm from Penang Island, Peninsular Malaysia (longitude $100^{\circ} 15^{\prime} \mathrm{E}$, latitude $5^{\circ} 17^{\prime} \mathrm{N}$ ) was chosen for this study. The goats were raised solely for their meat. Only adult, non-pregnant and non-lactating goats were selected. Also, the goats used showed mean nematode fecal egg counts exceeding 150 eggs per gram (EPG).

Goats were allocated into 3 groups, each group consisting of 10 goats; the first group was the control, the second treated with closantel, and the third given A.indica plant diet. All goats were weighed before (pretreatment) and after treatment (posttreatment). Food and water were provided ad libitum.

\section{Collection and preparation of plants}

Fresh $A$. indica leaves were collected from trees from various sites of Penang Island, Peninsular Malaysia. The leaves were separated from the stalks and fed fresh to the treated group twice weekly before sample collection. Each goat was given $3 \mathrm{~g}$ of $A$. indica leaves per $\mathrm{kg}$ of body weight.

\section{Anthelminthic administration}

The goats for anthelminthic treatment were treated with $1 \mathrm{ml} / 20 \mathrm{~kg}(2.5 \mathrm{mg} / \mathrm{kg})$ of closantel (Flukiver 5 Inject ${ }^{\circledR}$ by Janssen Pharmateuticals) injected subcutaneously under the loose skin of the neck in a single dose.

\section{Fecal egg counts}

Fecal samples were collected per rectum twice weekly for a period of 6 weeks (duration of pre-treatment to post-treatment period) and the number of eggs per gram of feces was estimated using a modified McMaster technique (Whitlock, 1948) with flotation in saturated sodium chloride. The remaining feces were pooled and cultured with vermiculites for infective larvae. One hundred randomly collected larvae were obtained from the culture and identified according to the descriptions of Dikmans \& Andrews (1933) and Gordon (1933).

\section{Fecal Egg Count Reduction Test (FECRT)}

Fecal samples were analyses by the Fecal Egg Count Reduction Test (FECRT) according to Coles et al. (1992). The FECRT provides estimation of the anthelminthic efficacy by comparing fecal egg counts (FECs) before and after treatment. Anthelminthic resistance was considered present if the FECR was less than $95 \%$ and the lower confident limit (CI) for the reduction was less than $90 \%$ (Coles et al., 1992).

\section{Statistical Analysis}

Descriptive statistics were produced using data analysis tools Microsoft Excel 2007 and SPSS 12.0 statistical software. Data for mean EPG and larval culture counts of the 
treated group were subjected to an analysis of variance (ANOVA). The differences in FEC and larval counts were determined using t-tests. The significant level for statistical tests was set to $\mathrm{P}<0.05$.

\section{Results and Discussion}

Figure.1 shows the mean EPG counts for both pre- and post-treatment groups. At the beginning of the study, all goats showed high egg counts. In the closantel group, the mean EPG was 3625 while the $A$. indica group showed a mean EPG of 4775 compared to 2250 of the control group. For the mean of post-treatment EPG count, the control group recorded a mean of 9225 . This value was slightly higher than that of posttreatment.

Treatment groups closantel and $A$ indica recorded mean EPGs of 2565 and 4571 respectively. Both treatment groups showed reductions in EPGs. There was no significant difference in egg counts $(\mathrm{P}>0.05)$ between control and closantel groups and also between control and $A$. indica groups.
Table 1 shows the fecal egg count reduction (FECR) for the closantel and A. indica groups. FECR was $29.2 \%$ for closantel and $4.3 \%$ for $A$. indica.

Fecal larvae cultures indicated that Haemonchus spp. was the dominant gastrointestinal parasite (Table 2). Other species recorded were Trichostrongylus spp., Oesophagostomum spp. and Cooperia spp. However, numbers of larvae for the different species varied greatly for all treatment groups.

Closantel treatment reduced all species of larvae except for Trichostrongylus spp (Table 3). A diet of $A$. indica succeeded in reducing the population of Haemonchus spp. (Table 4).

Haemonchus spp. seemed to be the most dominant species in the control group. Closantel treatment reduced all species except for Trichostrongylus spp. while treatment with $A$. indica group showed inconsistent generic larva prevalence.

Table.1 Fecal Egg Count Reduction (FECR) for Closantel and A. indica groups

\begin{tabular}{|c|c|c|c|}
\hline Treatment & Pre-FEC & Post-FEC & FECR [\%] \\
\hline Closantel & 3625 & 2566 & 29.2 \\
\hline A. indica & 4775 & 4572 & 4.3 \\
\hline
\end{tabular}

Table.2 Percentage mean of larvae for each treatment group.

\begin{tabular}{|c|c|c|c|}
\hline Larvae species & \multicolumn{3}{|c|}{ Percentage mean of larvae } \\
\hline & Control & Closantel & A. indica \\
\hline Haemonchus spp. & 52.7 & 29.4 & 41.8 \\
\hline Trichostrongylus spp. & 19.6 & 44.7 & 6.9 \\
\hline Cooperia spp. & 16.6 & 15.5 & 28.9 \\
\hline Oesophagostomum spp. & 11.1 & 10.4 & 22.4 \\
\hline
\end{tabular}


Table.3 Percentage mean of larvae for pre- and post-treatment for closantel treatment

\begin{tabular}{|c|c|c|c|}
\hline Larvae species & \multicolumn{2}{|c|}{ Percentage (\%) mean of larvae species } & \\
\hline & Pre-treatment & Post-treatment & \% of reduction \\
\hline Haemonchus spp. & 44.25 & 22.00 & 50.28 \\
\hline Trichostrongylus spp. & 14.75 & 59.63 & -304.24 \\
\hline Cooperia sp. & 25.25 & 10.63 & 52.25 \\
\hline Oesophagostomum sp. & 15.75 & 7.75 & 50.79 \\
\hline
\end{tabular}

Table.4 Percentage mean of larvae for pre- and post-treatment for A. indica treatment

\begin{tabular}{|c|c|c|c|}
\hline Larvae species & \multicolumn{2}{|c|}{ Percentage (\%) mean of larvae species } & \\
\hline & Pre-treatment & Post-treatment & $\%$ of reduction \\
\hline Haemonchus sp. & 51.25 & 37.25 & 27.32 \\
\hline Trichostrongylus sp. & 5.25 & 7.75 & -47.62 \\
\hline Cooperia sp. & 22.00 & 32.38 & -47.16 \\
\hline Oesophagostomum sp. & 21.50 & 22.88 & -6.40 \\
\hline
\end{tabular}

Fig.1 Pre- and post-treatment mean fecal egg count (FEC)

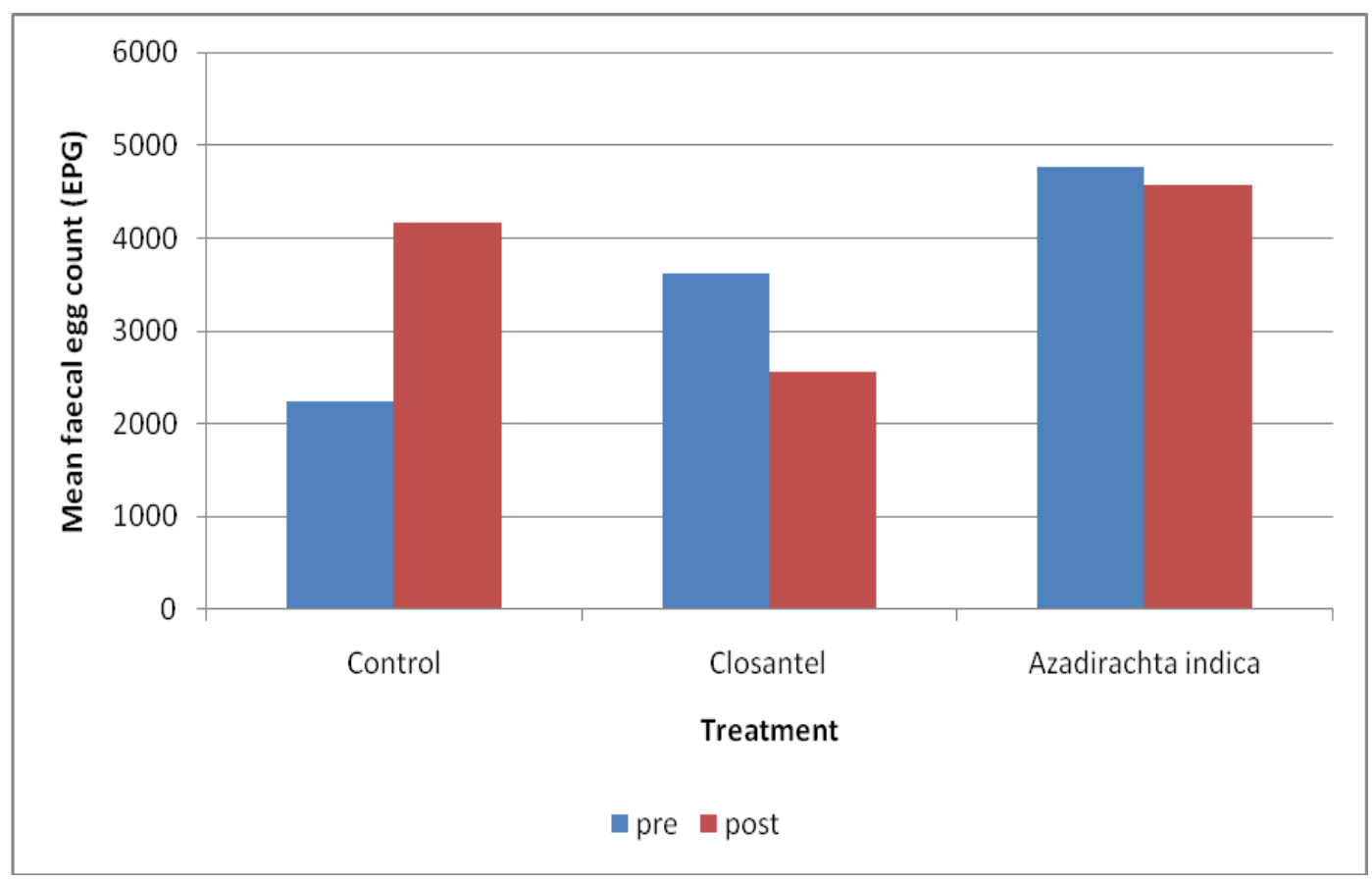

In this study, the trichostrongylid nematodes that were recovered in all groups were Haemonchus spp., Trichostrongylus spp., Cooperia spp., and Oesophagostomum spp., with Haemonchus spp. being dominant over the others. Based on FECRT, closantel has a low efficacy of $29.2 \%$ and did not reduce the total number of nematode eggs, as previously reported in the country by Pandey \& Sivaraj (1994) and Chandrawathani et al., (1999) where this drug had failed to control trichostrongylid nematodes both in sheep and goats, possibly attributed to the development of resistance to the closantel. 
There were several factors that have caused this resistance problem. Lack of anthelminthic history from sheep and goat importers into the country had possibly worsened the problem. The introduction of goats carrying resistant worms into farms with non-resistant worm populations may have promoted the spreading of resistance in the country. Also, imported animals were sometimes not quarantined adequately before being integrated into the farms. The other factor that had resulted in the resistance problem was the long-term use of the same anthelminthic without verifying its efficacy, thus leading to an increase in the proportion of resistant nematodes in the farms. Also, the goats used in the present study were imported from neighboring Thailand and resistance records of these imported animals were unclear.

It is clear that anthelminthic resistance in Malaysia is escalating and the dependence on anthelminthic to combat worms should be minimized; potentials of plants which possess anthelminthic activity should be explored (Githiori et al., 2003; Chandrawathani et al., 2006). However, based on this study, A. indica plant had a low efficacy against gastrointestinal parasites as indicated by the FECR, concurring with the findings of Khadijah et al., (2005) who had used pellet $A$ indica as well as fresh leaves of the plant. Thus, in conclusion, other methods of biological control should be explored such as the use of nematophagous fungi as reported by Chandrawathani et al., (2002, 2003, 2004).

\section{References}

Coles, G.C., Bauer, C., Borgsteede, F.H.M., Geerts, S., T.R.K., Taylor, M.A. Waller, P.J. 1992. WAAVP methods for the detection of anthelmintic resistance in nematodes of veterinary importance. Vet. Parasitol.,
44: 35-44

Chandrawathani, P., Parameswaran, S. \& Asiah-Naina, M. 1994. Antiparasitic

29 drugs used in selected sheep and goat farms in West Malaysia. J. Vet. Malaysia, 6: 61-64.

Chandrawathani, P., Adnan, M., Waller, P.J. 1999. Anthelmintic resistance in sheep and goat farms on Peninsular Malaysia. Vet. Parasitol., 82: 305-310.

Chandrawathani, P., Jamnah, O., Waller, P.J., Hoglund, J., larsen, M. \& Zahari, W.M. 2002. Nematophagous fungi as a biological control agent for nematode parasites of small ruminants in Malaysia; a special emphasis on Duddingtonia flagrans. Vet. Res., 33: 685-696

Chandrawathani, P., Jamnah, O., Waller, P.J., Larsen, M., Gillespie, A.T. \& Zahari, W.M. 2003. Biological control of nematode parasites of small ruminants in Malaysia using the nematophagous fungus Duddingtonia flagrans. Vet. Parasitol., 117: 173183.

Chandrawathani, P., Jamnah, O., Adnan, M., Waller, P.J., Larsen, M. \& Gillespie, A.T. 2004. Field studies on the biological control of nematode parasites of sheep in the tropics, using the microfungus Duddingtonia flagrans. Vet. Parasitol., 120: 177187.

Chandrawathani, P., Chang, K.W., Nurulaini, R., Waller, P.J., Adnan, M., Zaini, C.M., Jamnah, O., Khadijah, S. \& Vincent, N. 2006. Daily feeding of fresh Neem leaves (Azadirachta indica) for worm control in sheep. Trop. Biomed., 23: 23-30.

Dikmans, G. and Andrews, J.S. 1933. A comparative morphological study of the infective larvae of the common nematodes parasitic in the alimnetary tract of sheep. Transactions American 
Microscopic Soc., 52: 1-25.

Dorny, P., Clarebout, E., Vercruysee, J., Sani, R.A., and Jalila, A. 1994. Anthelmintic resistance in goats in Peninsular Malaysia. Vet. Parasitol., 55: 327-343.

Githiori, J.B., Hoglund., J., Waller, P.J. \& Baker, R.L. 2003. Evaluation of Anthelminthic properties of extracts from some plants used as livestock dewormers by pastoralist and smallholder farmers in Kenya against Heligmosomoides polygyrus infections in mice. Vet. Parasitol., 118: 215216.

Gordon, H.M. 1933. Differential diagnosis of the larvae Ostertagi spp. and Trichostrongylus spp. of sheep. Australian Vet. J., 9: 223-237.

Khadijah, S., Wahab, A.R., Chandrawathani, P. \& Wan Zahari, M. 2005. Pen study of Neem pellets (Azadirachta indica) for helminth control in sheep. Proceeding of $41^{\text {st }}$ Annual Scientific Seminar "Natural Products in the mangaement of Tropical Diseases".
Kuala Lumpur.

Pandey, V.S. and Sivaraj, S. 1994. Anthelminthic resistance in Haemonchus contortus from sheep in Malaysia. Vet. Parasitol., 53: 67-74.

Rahman, W.A. 1994. Survey for drugresistant trichostrongyle nematodes in ten commercial goat farms in West Malaysia. Trop. Anim. Health Prod., 26: $235-238$

Sivaraj, S., Dorny, P., Vercruysse, J. \& Pandey, V.S. 1994. Multiple and multi-generic anthelmintic resistance on on sheep farm in Malaysia. Vet. Parasitol., 55: 159-165.

Waller, P.J. and Thamsborg, S.M. 2004. Nematode control in 'green' ruminant production systems. Trends Parasitol., 20: 493-497.

Whitlock, J.H. 1948. Some modifications of the McMaster egg counting technique and apparatus. J. Council for Scientific and Industrial Res. Australia, 21: 177180.

\section{How to cite this article:}

Wahab A. Rahman. 2016. Comparing the Efficacy of Closantel (An Anthelmintic Drug) and Azadirachta indica (Neem Plant) Diet in Controlling Trichostrongylid Nematode Parasites in Goats in Malaysia. Int.J.Curr.Microbiol.App.Sci. 5(10): 565-570.

doi: http://dx.doi.org/10.20546/ijcmas.2016.510.063 